\title{
Fabrication of an all-metal atomic force microscope probe
}

\author{
Rasmussen, Jan Pihl; Tang, Peter Torben; Hansen, Ole; Møller, Per; Sander, Curt
}

Published in:

Proceedings of Transducers 97

Link to article, DOI:

10.1109/SENSOR.1997.613686

Publication date:

1997

Document Version

Publisher's PDF, also known as Version of record

Link back to DTU Orbit

Citation (APA):

Rasmussen, J. P., Tang, P. T., Hansen, O., Møller, P., \& Sander, C. (1997). Fabrication of an all-metal atomic force microscope probe. In Proceedings of Transducers 97 (Vol. 1, pp. 463-466). IEEE.

https://doi.org/10.1109/SENSOR.1997.613686

\section{General rights}

Copyright and moral rights for the publications made accessible in the public portal are retained by the authors and/or other copyright owners and it is a condition of accessing publications that users recognise and abide by the legal requirements associated with these rights.

- Users may download and print one copy of any publication from the public portal for the purpose of private study or research.

- You may not further distribute the material or use it for any profit-making activity or commercial gain

- You may freely distribute the URL identifying the publication in the public portal 


\title{
Fabrication of an All-Metal Atomic Force Microscope Probe
}

\author{
Jan P. Rasmussen ${ }^{a}$, Peter T. Tang ${ }^{b}$, Curt Sander ${ }^{c}$, Ole Hansen $^{a} \&$ Per Møller \\ ${ }^{a}$ Microelectronics Centre, Technical University of Denmark, DK-2800 Lyngby \\ ${ }^{b}$ Institute of Manufacturing Engineering, Building 425, Technical University of Denmark, DK-2800 Lyngby \\ ${ }^{c}$ DME Danish Micro Engineering A/S, Transformervej 12, 2730 Denmark
}

Keywords: AFM, STM, Electroplating, Thick Resist

\section{SUMMARY}

This paper presents a method for fabrication of an all-metal Atomic Force Microscope probe (tip, cantilever and support) for optical read-out, using a combination of silicon micromachining and electroforming. The paper describes the entire fabrication process for a nickel AFM-probe. In addition the first measurements with the new probe are presented.

\section{INTRODUCTION}

The single most important component in an AFM is the flexible force sensing cantilever with a sharp tip at the end, also called an AFM-probe. A conductive AFM-probe is a very useful component because it also makes it possible to use the device as a Scanning Tunnelling Microscope (STM) probe, or for simultaneous recording of AFM and STM signals. In this case it is possible to obtain a high resolution topography and surface conductance image in one scan. Even more interesting is the possibility to use the device for STM lithography.

Today most of the commercially available AFM-probes are either fabricated in Silicon Nitride $\left(\mathrm{Si}_{3} \mathrm{~N}_{4}\right)$ or Silicon dioxide $\left(\mathrm{SiO}_{2}\right)$ using Silicon as a mould [1] or directly in Silicon [2,3]. In order to use these probes in the combined AFM/STM mode it is necessary to deposit a conductive film (e.g. physical vapour deposition) on the cantilever and tip. This is not without problems. Often the deposition of the conductive film introduces stress in the cantilever which will make it bend. Another problem is that the deposition changes the shape of the tip and often results in a less sharp tip.

The all-metal AFM-probe described in this paper is fabricated using a combination of silicon micromachining and electroforming or more precise we electroplate the component using silicon and thick photoresist as a mould. A significant difference between this and other AFM-probes for optical readout, is that the probe is made entirely of metal. In a related work a support structure is plated on a $\mathrm{Si}_{3} \mathrm{~N}_{4}$-cantilever and tip [4]. A third group [5] have made a Lateral Tunnelling Unit (LTU) in electroplated metal, but their approach can not be used in a system with optical read-out. Furthermore the entire cantilever was sharpened in a post-process (electrolytic polishing after the probe was released). The probe of this presentation is born with a sharp tip.

\section{FABRICATION PROCESS}

In fig. 1 the process sequence is sketched. The mould for the tip is defined in silicon using traditional silicon micro machining; i.e. anisotropic silicon etching $\left(\mathrm{KOH}, 28 \mathrm{wt} \%, 80^{\circ} \mathrm{C}\right)$ using silicon dioxide as etch-mask. This results in a pyramidal tipmould defined by the (111) crystal planes of the silicon. This silicon tip-mould is sharpened by growing a non uniform, low temperature $\left(950^{\circ} \mathrm{C}\right)$, wet thermal oxide $(4000 \AA)$ [6].

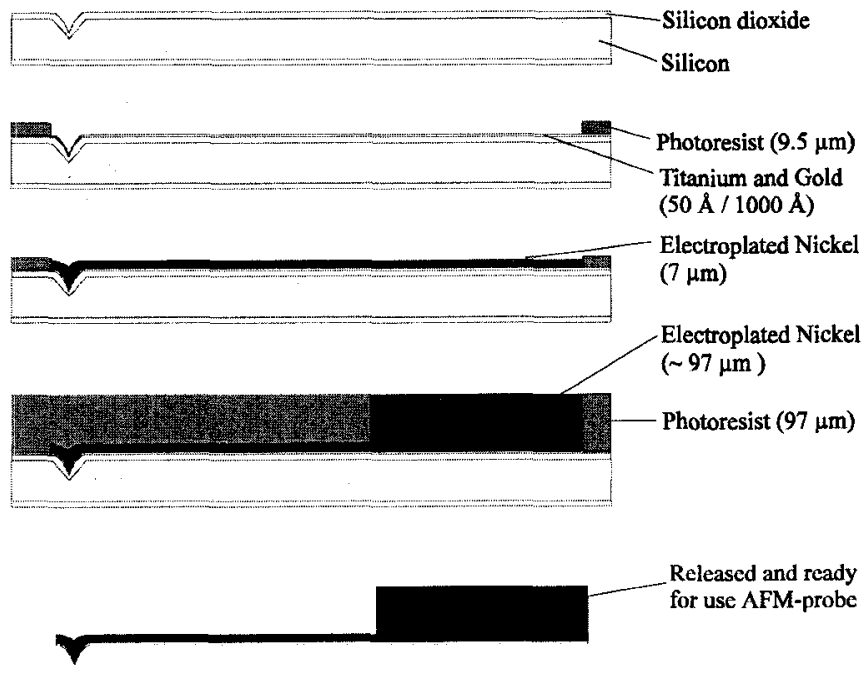

Figure 1. Fabrication process. The sequence is described in detail in the text.

A plating base (adhesion and conducting layer for the plating process) of $50 \AA$ titanium and $1000 \AA$ gold is deposited by physical vapour deposition. The cantilever and tip are electroplated in Nickel using the $\mathrm{KOH}$-etched cavity and a 9.5 $0.1 \mu \mathrm{m}$ thick photoresist pattern as a mould. As photoresist the AZ 4562 from Hoechst is used. The resist is deposited and then spun at $2000 \mathrm{rpm}$. in $20 \mathrm{sec}$. Hereafter the resist is baked on a hotplate at $100^{\circ} \mathrm{C}$ in $5 \mathrm{~min}$. and exposured in a mask aligner using optical contact printing. In the electroplating process the thickness of each cantilever is typically set to $7 \mu \mathrm{m}$. The support structure for the cantilever is electroplated in nickel using a $97 \pm 2 \mu \mathrm{m}$ thick photoresist pattern as mould. The 


\section{B3.05}

photoresist is the same as before but the processing is a little different. Four layers of app. $25 \mu \mathrm{m}$ resist is stacked on top of each other. In each layer the resist is spun at $2000 \mathrm{rpm}$. in $4 \mathrm{sec}$. followed by an intermediate bake on a hotplate at $90^{\circ} \mathrm{C}$ in 3 min. Hereafter the resist is prebaked in a conv. oven at $100^{\circ} \mathrm{C}$ in 3 hours (including ramp). This results in a thick "resist-film" of app. $97 \pm 2 \mu \mathrm{m}$. The resist is exposed in a mask aligner using contact printing. The total thickness of the plated support structure is usually equal to the thickness of the photoresist, but this is not a critical step.

At last the silicon wafer is dissolved in a selective wet etch $\left(\mathrm{KOH}, 28 \mathrm{wt} \%, 60^{\circ} \mathrm{C}\right.$ ), and the AFM-probes can now be released one by one with a pair of tweezers and are ready for use. Fig. 2 shows a SEM photo of some finished AFM-probes, and fig. 3 shows a close-up of a cantilever and tip.

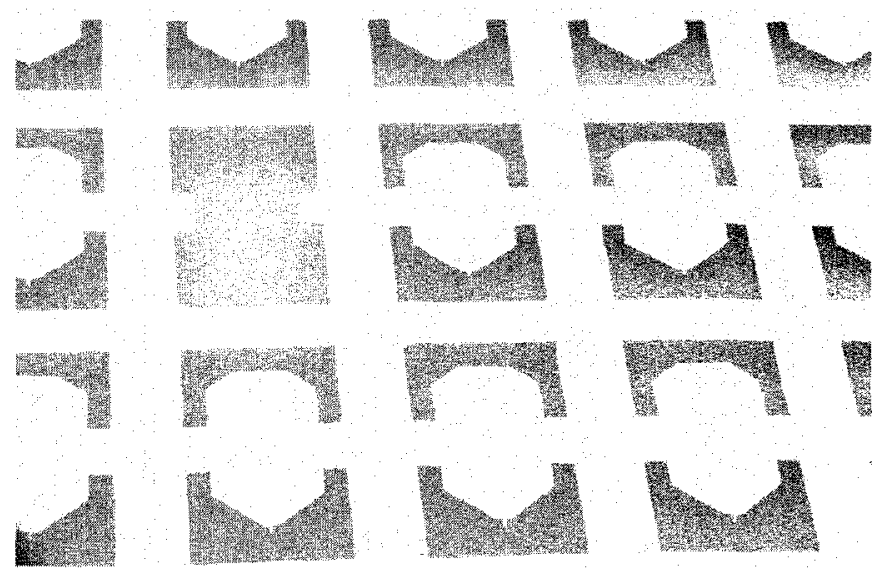

Figure 2. SEM-micrograph of some "ready for use" AFMprobes. It is possible to remove a probe from the frame (carrier) with just a pair of tweezers. Each cell is $3.4 \times 6 \mathrm{~mm}$.

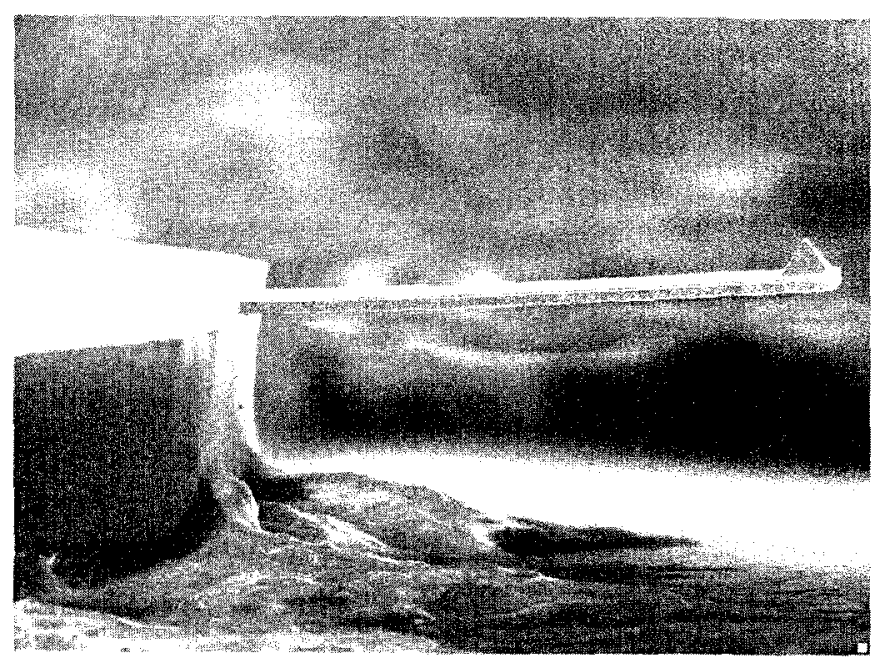

Figure 3. SEM-micrograph of a all-nickel cantilever, tip and support. The cantilever is $200 \mu \mathrm{m}$ long, $30 \mu \mathrm{m}$ wide and $4 \mu \mathrm{m}$ thick. The height of the tip is $10 \mu \mathrm{m}$.

\section{Electroplating}

As mentioned before the probes are fabricated in nickel using an electroforming process. There are a lot of different electrolytes to chose from, but in this project we have used the nickel sulphamate bath which is the most widely used nickel bath for electroforming. The nickel sulphamate bath (previously described in [7]) basically consists of:

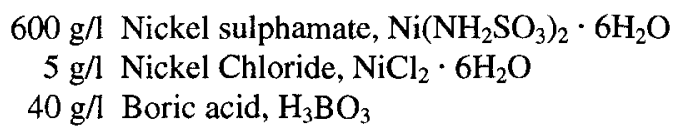

The anodes are made of sulphur alloyed nickel $(0.025 \% \mathrm{~S})$ and the $\mathrm{pH}$ is maintained at 4.5 . Temperatures between $36^{\circ} \mathrm{C}$ and $57^{\circ} \mathrm{C}$ has been used. Furthermore a commercial wetting agent and a brightener are used in the bath. It is in general necessary to reduce stress in the deposit to a minimum to avoid problems with the function and/or processing of the components. For this purpose the stress reducing additive naphthalene $1,3,6$ sulphonic acid is applied. By proper control of the additives, current density and plating temperature, it is possible to electroplate a nickel thin-film with almost any type and amount of stress, including "stress-free". Fig. 4 shows stress at room temperature in a electroplated nickel thin-film (on a $500 \pm 50 \mu \mathrm{m}$ thick $4 "$-silicon wafer) as a function of current density and the amount of the stress reducing additive.

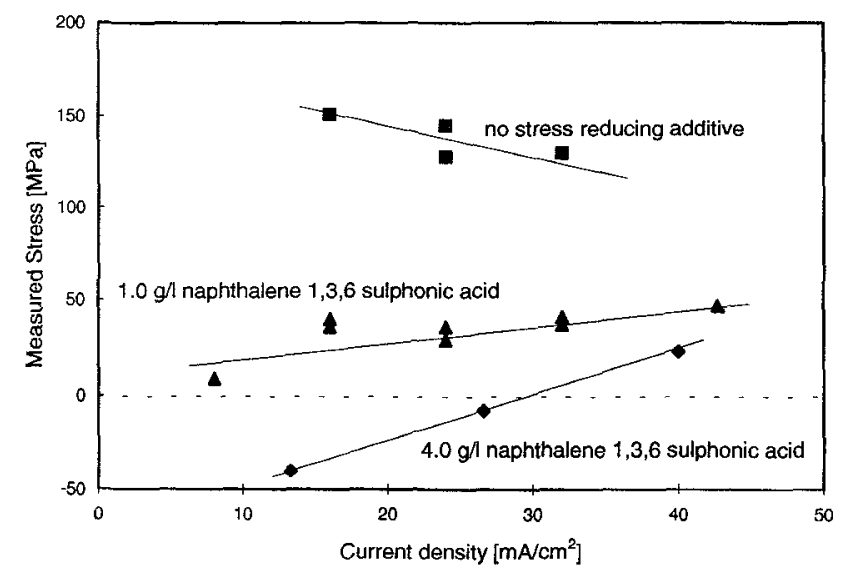

Figure 4. Measured stress at room temperature in electroplated nickel thin-films (bath described in text) on silicon as function of current density and the concentration of the stress reducing additive naphthalene 1,3,6 sulphoric acid. The bath is operated at $43 \pm 0.1^{\circ} \mathrm{C}$.

The temperature is also a parameter which need proper control. Any change in temperature will move/change the shape of the curves in fig. 4.

In the experiments from fig. 4 a thin-film $(2-4 \mu \mathrm{m})$ without pattern is electroplated on the entire wafer. Stoney's expression for stress [8] is then used to calculate the stress in the nickel film. The input parameters are the thickness of the plated thinfilm and substrate, the modulus of elasticity of the substrate and 
the change in curvature of the substrate before and after electroplating. The change in curvature is measured at room temperature on a mechanical profiler. Since the material distribution of the electroplated nickel is not perfect, the calculated stress is an average stress value based on an average thickness calculated from the weight gain. We expect that the uncertainty on the measurement/calculation is in the order of \pm $10 \mathrm{MPa}$.

The difference in the thermal expansion of the different materials involved, will also cause some problems with stress. This is especially true when working with thick metal layers on top of silicon. As an example the calculated introduced stress in a nickel thin film on a thick silicon substrate that is cooled down from $43^{\circ} \mathrm{C}$ (typical plating temperature) to $22^{\circ} \mathrm{C}$ (room temperature) is approximately $62 \mathrm{MPa}$ or almost $3 \mathrm{MPa} /{ }^{\circ} \mathrm{C}$.

In general we are plating with compressive stress in the nickel deposit during the plating process (as plated in the bath), thus resulting in tensile stress in the deposit after cooling down to room temperature. This is done to minimise stress in the materials to avoid that the nickel deposit will peel-off during or after plating. After the last plating step the silicon wafer is dissolved, ending up with the ready for use all-metal AFMprobes.

You would expect that a stress gradient in the plating direction will cause a bending of the cantilevers. But we see no (or in rare cases a very small) bending of the cantilever.

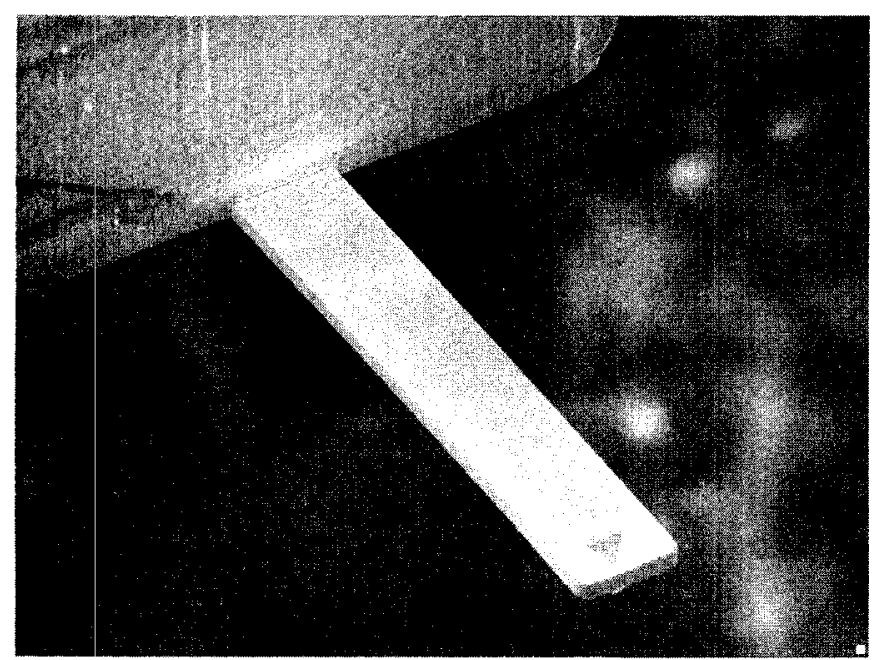

Figure 5. SEM-micrograph of the back side of a cantilever.

The roughness of the plated material is increasing with the thickness. But in general there has been no problems with the quality of the reflection from the back side of the cantilevers.

The thickness of the cantilevers is controlled in the plating process. The total thickness variation of the cantilevers across the entire 4 "-wafer is within $10 \%$, but it is better than $2 \%$ in the central 2"-area. The design of the photomask for the resist mould and the design for the wafer plating holder are very important parameters for the thickness distribution of the electroplated deposit across the wafer. A special holder with an aperture (a so called "current thief") around the wafer is used.
The aperture is at the same electrical potential as the wafer during plating. This results in a more even thickness distribution. Another problem is the pattern distribution/density across the wafer. Generally the thickness is smaller in areas with a high pattern density (large plating area) than in areas with a small pattern density. This problem is reduced by a rational mask design with a homogenous pattern distribution.

\section{Characterisation}

Fig. 6 shows a close-up of a tip. The tip is covered with a thin layer of gold (from the plating base) and the radius of curvature (after release) is better than $100 \mathrm{~nm}$. Currently effort is being made to improve the radius of curvature.

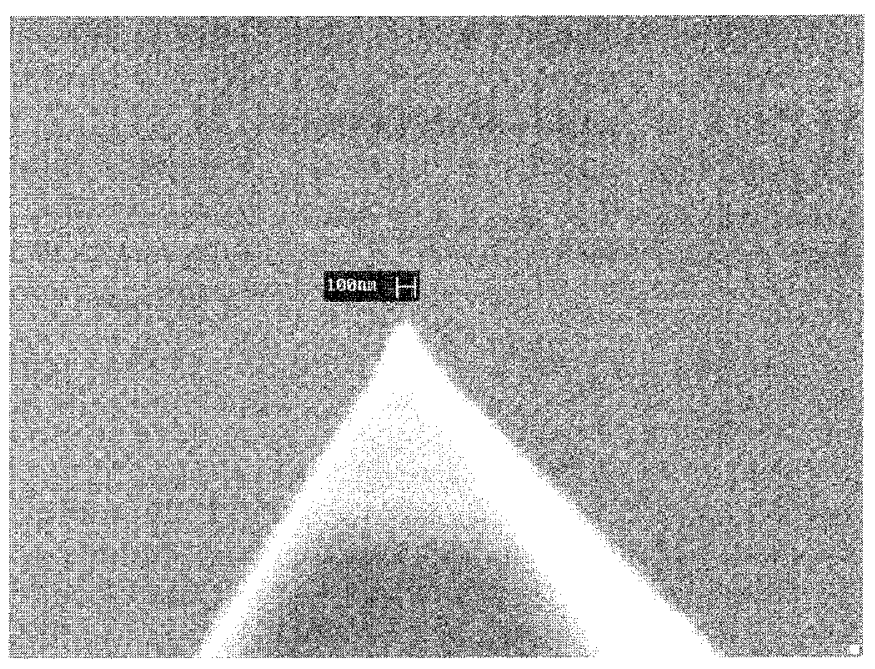

Figure 6. SEM-micrograph of a close-up of a tip. The radius of curvature is better than $100 \mathrm{~nm}$.

It is important to specify a very low absolute uncertainty on the dimensions on the tip-mask (i.e. the photomask that defines the etchmask for the tip mould). In order to obtain a perfect tip mould, the tip-mask must be inscribed in a perfect square aligned along the trace of the (111) plane. The reason for that is that the absolute uncertainty on the dimensions are reproduced in the tip with the possible result of a non sharp tip. This has caused a lot of problems in our work.

One of the drawbacks of a pyramidal tip is the low aspect ratio. Some work has been done to improve this, and a novel tip shape has been developed, by combining dry and wet etching of the mould (i.e. a silicon wafer) [9].

The thickness of the cantilevers are typically set to $7 \mu \mathrm{m}$. This will give a theoretical resonance frequency of $140 \mathrm{kHz}$ and a stiffness of $60 \mathrm{~N} / \mathrm{m}$ (length: $200 \mu \mathrm{m}$, width: $30 \mu \mathrm{m}$ ). Measured values agree with these predictions.

Fig. 7 shows the first measurement with the new AFM-probe, on a grating (test target) with a periodicity of $3 \mu \mathrm{m}$ and a height of $680 \mathrm{~nm}$. The total area of the scan is $10 \times 10 \mu \mathrm{m}$. The AFM image, is obtained using a DME dualscope ${ }^{\mathrm{TM}}$ with the all-nickel cantilever operated in dynamic mode. 


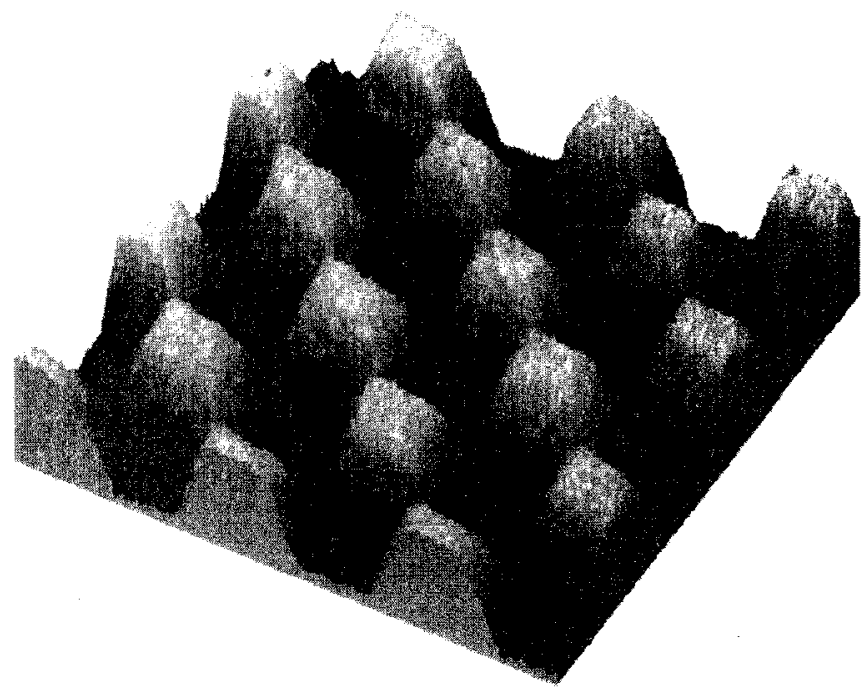

Figure 7. AFM image of a test target $(10 \times 10 \mu \mathrm{m})$ obtained in a DME dualscope $e^{T M}$ with the all-nickel cantilever operated in dynamic mode.

\section{CONCLUSION}

A method for fabrication of all-metal AFM-probes has been demonstrated. The fabrication process involves a combination of silicon micromachining and electroforming. Initial characterisation experiments shows that the probe perform as predicted (i.e calculations using modulus of elasticity for Nickel). The fabrication method is interesting because it makes it possible to produce relatively cheap conducting AFM-probes using a rather simple technology. Even more interesting is the possible use of the nickel-probes for STM lithography. Also Magnetic Force Microscopy applications are possible, using a similar fabrication method but with an electroplated tip of a soft ferromagnetic material (e.g. PermAlloy) and with a nonmagnetic cantilever (e.g. amorphous nickel/phosphor (12\% P)).

\section{ACKNOWLEDGEMENTS}

The authors wish to thank A. Boisen, M.E. Benzon and K. Birkelund for assistance and useful discussions in this project.

\section{REFERENCES}

[1] T.R. Albrecht, S. Akamine, T.E. Carver and C.F. Quate, J. Vac. Sci. Technol., vol. A8 (1990), pp. 3386-3396.

[2] O. Wolter, T. Bayer and J. Greschner, J. Vac. Sci. Technol. vol. B 10 (1991), pp. 1353-

[3] A. Boisen, O. Hansen and S. Bouwstra, J. Micromech. Microeng., vol. 6 (1996), pp. 58-

[4] H.J. Mamin et al., Solid-state Sensor and Actuator Workshop, Hilton Head, South Carolina (1994), pp. 1720.

[5] T. Hirano et al., Jpn. J. Appl. Phys., Vol. 33 (1994) pp. 1202-1208
[6] S. Akamine, C.F. Quate, J. Vac. Sci. Techn. B 10(5) (1992), pp. 2307-2310.

[7] P.T. Tang, M.E. Benzon, J.P. Rasmussen and F.S. Fontenay, AESF, proc. of Sur/Fin'96, Cleveland (1996), pp. 627-636.

[8] G.G.Stoney, Proc. Roy. Soc., London, vol. A82 (1909), pp. 192-

[9] A.Boisen, J.P.Rasmussen, O.Hansen and S.Boustra, Microelec. Eng., vol. 30 (1996), pp. 579-582. 